Andrei A. Orlov

\title{
Yahoel and Metatron
}

\section{Aural Apocalypticism and the Origins of Early Jewish Mysticism}

[Yahoel und Metatron. Auratische Apokalyptik und die Ursprünge der frühjüdischen Mystik.]

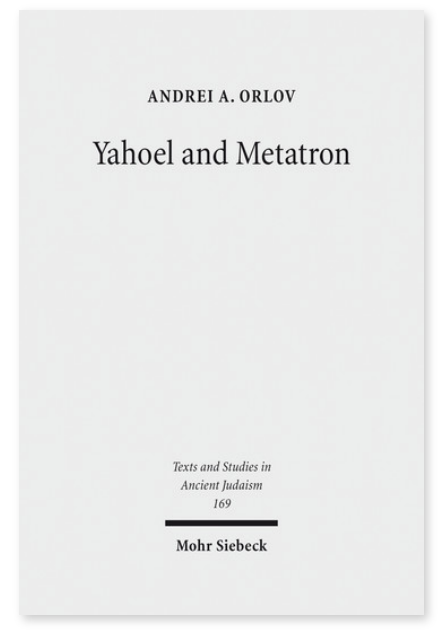

2017. XII, 238 Seiten. TSAJ 169

ISBN 978-3-16-155448-3

DOI 10.1628/978-3-16-155448-3

eBook PDF 134,00 €

ISBN 978-3-16-155447-6

Leinen $134,00 €$
Veröffentlicht auf Englisch.

Andrei A. Orlov untersucht in dieser Arbeit jüdische apokalyptische Überlieferungen über den Engel Yahoel und zeichnet deren konzeptionellen Einfluss auf die Entwicklung späterer rabbinischer und hekhaloter Überzeugungen bezüglich des hohen Engels Metatron nach. Der Autor zeigt, dass die Figur Yahoel, welche in der jüdischen Apokalyptik mit der unverkennbaren auratischen Ideologie des göttlichen Namens assoziiert wurde, ein wichtiger konzeptioneller Schlüssel ist: nicht nur, um die Entwicklung der Metatron-Überlieferung zu erläutern, sondern auch, um die Ursprünge der charakteristischen auratischen Ideologie zu verstehen, die in frühjüdischen mystischen Berichten auffällt. Andrei A. Orlov legt nahe, dass die auratische Form der jüdischen Apokalyptik einen ausschlaggebenden und prägenden Einfluss auf die Entwicklung der frühjüdischen Mystik ausübte.

Andrei A. Orlov Born 1960; 1990 PhD at Institute of Sociology (Russian Academy of Sciences); 1995 MA and 1997 MDiv at Abilene Christian University (TX); 2003 PhD at Marquette University (WI); Professor of Judaism and Christianity in Antiquity, Marquette University (WI).

\section{Jetzt bestellen:}

https://mohrsiebeck.com/buch/yahoel-and-metatron-9783161554483?no_cache=1

order@mohrsiebeck.com

Telefon: +49 (0)7071-923-17

Telefax: +49 (0)7071-51104 